\title{
Addressing Anemia in Pregnant Women and School Children through a Field Tested Novel Strategy
}

\author{
Andezhath Kumaran Susheela ${ }^{1}$ Chandrawati Kumari ${ }^{1}$ \\ ${ }^{1}$ Fluorosis Research and Rural Development Foundation, Patparganj, \\ Delhi, India \\ Address for correspondence Andezhath Kumaran Susheela, PhD, \\ FAMS, FASc, FNASc, Fluorosis Research and Rural Development \\ Foundation, B1, Saransh Apartment, 34 IP Extension, Patparganj, \\ Delhi 110092, India (e-mail: frnrdf.aks@gmail.com).
}

\begin{abstract}
Objective To introduce a protocol for improving hemoglobin $(\mathrm{Hb})$, rectifying anemia in pregnant women and school children through practice of interventions.

Materials and Methods Pregnant women $(n=3,262)$ visiting antenatal clinics (ANCs) in two government hospitals in New Delhi were screened for Hb using a hemoglobinometer. Those anemic with $\mathrm{Hb}<12.0 \mathrm{~g} / \mathrm{dL}$ were tested for fluoride in urine samples, using ion meter with $\mathrm{F}^{-}$-specific electrode. Those who are anemic with high urine fluoride level (UFL $\geq 1.0 \mathrm{mg} / \mathrm{L}$ ) were tested for fluoride in drinking water. If water fluoride is $\geq 1.0 \mathrm{mg} / \mathrm{L}$, a large number of samples were tested from the neighborhood water sources. Besides, the pregnant women were advised to use water from safe sources for cooking and drinking purposes. The pregnant women, who visited ANCs were retested for $\mathrm{Hb}$ and UFL during every visit and introduced to diet editing and diet counseling. Body mass index was calculated initially and prior to delivery. Delivery outcome information was collected and recorded from labor room register.

Girls and boys $(n=2,420)$ attending six schools in the national capital were inducted in the study. "Informed consents" were obtained from the parents of the recruited children and the principal of the school. The "ascent" was obtained from the children. The protocol comprised screening for $\mathrm{Hb}$ and testing of fluoride levels in the urine and drinking water. Diet editing and counseling were introduced to parents/mothers during parentteacher meetings and impact of the interventions was assessed at 1, 3, and 6 months postintervention and the recorded data were evaluated and analyzed statistically.

Results It was observed that $83 \%$ of pregnant women in whom anemia was corrected delivered normal birth weight infants $(2.5-3.89 \mathrm{~kg})$. The $17 \%$ women in whom anemia was not corrected gave birth to low birth weight infants $(1.87-2.48 \mathrm{~kg})$. The school children in whom the diet editing was used as an intervention showed statistically significant enhanced $\mathrm{Hb}$ levels. These children did not require weekly iron and folic

Keywords

- anemia

- hemoglobin

- pregnancy

- children

- water

- urine fluoride level acid supplementation. It appears that educating parents to provide nutrient-rich food for correcting anemia seems to be an important intervention.

Conclusion Fluoride from water, food, beverages, use of rock salt with high $\mathrm{F}^{-} 157 \mathrm{ppm}$ in cooking and churans when withdrawn, structural changes in the gastrointestinal system was rectified, thus enhanced absorption of nutrients. The nation should have a meaningful protocol to do justice to pregnant women and school children afflicted with anemia.
\end{abstract}

DOI https://doi.org/

$10.1055 / \mathrm{s}-0040-1710161$

ISSN 0379-038X.
(C)2020 National Academy of

Medical Sciences (India)
License terms

()(1) $\odot \circledast$ 


\section{Introduction}

How long women and adolescent girls in India have to wait to get their health problems caused due to low hemoglobin (Hb) corrected? The national program focusing on iron and folic acid supplementation (IFS) to pregnant women visiting Antenatal Clinics (ANCs) commenced almost four decades ago. ${ }^{1-3}$ Besides, since 2012, school children have been introduced to weekly iron and folic acid supplementation (WIFS). In spite of these massive efforts and investments, there is still no light at the end of the tunnel. What are the reasons? Until now, the focus has been on iron deficiency and nutritional supplementation through tablets and improved diet, and mid-day meals in schools were considered the way forward.

Maternal and newborn/infant mortality besides low birth weight infants have long been plagued the nation. Commendable work on minimizing maternal mortality ratio (MMR) and infant mortality rate commenced in India since 1980s. However, India missed achieving the millennium development goals (MDGs) until 2015. The hopes are now pinned on Sustainable Development Goals (SDGs) by 2030. The nation needs policy decision to introduce a novel strategy field tested and successful for correction of anemia in pregnant women and school children.

Considerable investments have been made by the Department of Science and Technology (DST) and the Department of Health Research (DHR) through the Indian Council of Medical Research (ICMR) in the recent past to investigate the problem of preventable anemia in pregnant women and school children, both girls and boys. The investigators chalked out a plan the way forward to achieve what the nation could not achieve so far. According to the novel strategy, the problem of anemia was addressed through a nonnutritional pathway to begin with to understand the implications. It was then followed by nutritional interventions which are essential for achieving sustainability. The nonnutritional pathway was focusing on an environmental toxin fluoride entering the body through drinking water and food. ${ }^{4-9}$ The role of the toxin in damaging the gastrointestinal (GI) system and preventing the absorption of nutrients was evident from the basic structural and functional studies performed earlier. ${ }^{10}$

The Fluorosis Research and Rural Development Foundation, which is possibly one of the very few organizations in India with the expertise and skills in addressing fluoride toxicity, has developed a protocol to address anemia and its rectification through elimination of $\mathrm{F}^{-}$toxin. Pregnant women from two hospitals and school children from six schools were studied to address the problem during the last decade. The strategies toward ending preventable maternal and infant mortalities due to gestational anemia and low birth weight infants are possible as adequate field testing and baseline data are available and announced for the benefit of the national/global scientific community.

The genesis of the novel strategy has its origin in investigations on nonulcer dyspepsia (NUD)/irritable bowel syndrome (IBS) in patients nonresponding to treatment and dates back to 1990s. The authors wish to revert to their investigations performed on patients with NUD/IBS. The patients were investigated for fluoride toxin consumed through untreated ground water. The ground water in India is highly toxic due to $\mathrm{F}^{-}>1.0 \mathrm{mg} / \mathrm{L}$ in 20 states and union territories and the maximum fluoride detected so far is $48.0 \mathrm{mg} / \mathrm{L}$. Samples of water, serum, and urine of patients with NUD/IBS were investigated for fluoride content. The protocol developed had a provision to rule out the possibility of Helicobacter pylori infection and Giardia lamblia and other relevant tests were also incorporated. ${ }^{11}$ As fluoride intake was high in sample group of patients compared with control group, upper GI endoscopy was done. The biopsy materials obtained were examined using routine histopathological procedures. Besides, the biopsy material was examined under scanning electron microscope (SEM) for morphology of the GI mucosa. As the results were highly informative, patients with skeletal fluorosis on high fluoride intake and patients with otosclerosis on fluoride therapy as positive controls were also investigated following the same protocol for critically evaluating the SEM observations. Withdrawal of $\mathrm{F}^{-}$entry to the body through drinking water and other sources was introduced as interventions. The patients with NUD/IBS recovered within a short interval of 5 to 10 days without any drug administration. Nutritive diet was promoted so that recovery is faster. The protocol designed and clinical investigations performed are reported in - Fig. 1. A series of publications revealing loss of microvilli, mucus production, and cracked clay appearance of the mucosal surface appeared in reputed international journals were the early contributions. ${ }^{12-17}$ These researches revealed the extensive damages caused to the body by high fluoride intake. These studies also led to the observation that IBS/NUD can be the earliest manifestations of fluoride toxicity and used for suspecting fluorosis. It was during early 2000, patients with fluorosis knocking at the doors of the Fluorosis Research and Rural Development Foundation for diagnosis and recovery were also investigated using the same protocol and followed up. The impact of nutritional intervention, promoting consumption of fruits, vegetables, and dairy products rich in antioxidants and vitamins were field tested in patients with fluorosis, and the impact on recovery of the patients were followed up. ${ }^{18,19}$ Patients with fluorosis who were investigated for $\mathrm{F}^{-}$intake through water and food continued to be an avenue for assessing $\mathrm{F}^{-}$toxicity effects on $\mathrm{Hb}$, serum, and urine fluoride levels (UFLs).

Attention drawn to use Hb level as a yardstick for assessing recovery of the patients from fluoride poisoning effects. These efforts were meaningful to assess the impact of the interventions. ${ }^{19-21}$ It is also important to point out at this juncture, fluoride entry to the body is more through food, beverages, and spices containing rock salt with 157 ppm $\mathrm{F}^{22}$ than water. Street food/junk food highly laced with rock salt for its aroma and tangy taste is popular among the communities of all states in India.

This communication with the earlier information is to logically explain, where the nation need to focus attention besides developing meaningful slogans such as "Anemia 


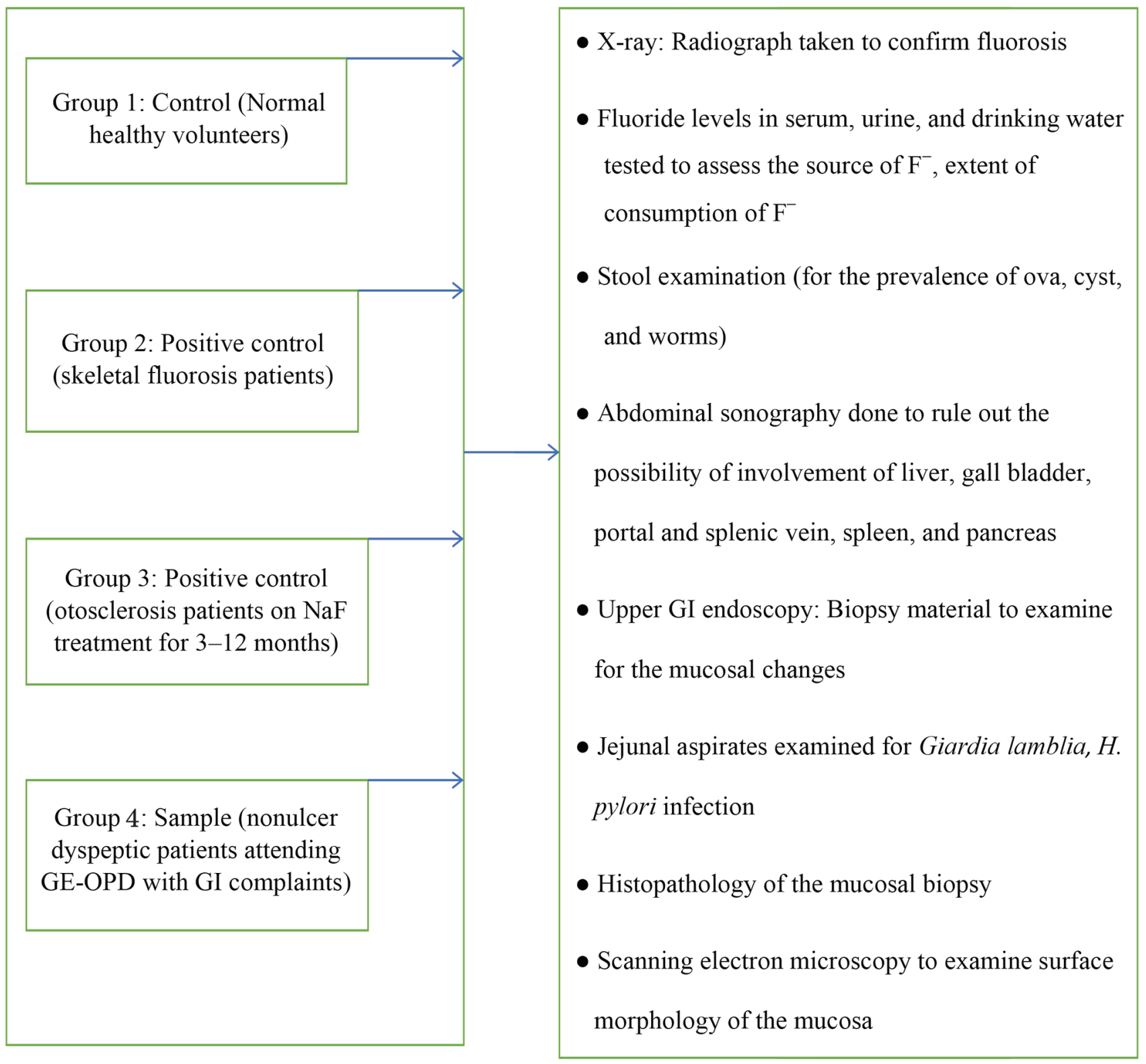

Fig. 1 Protocol drawn up to investigate nonulcer dyspeptic complaints due to consumption of excess fluoride. (This image is provided courtesy of Prof. Rakesh Tandon, MD, PhD, then the sub-dean and head of the Department of Gastroenterology in the All India Institute of Medical Sciences.)

Mukt Bharat" as the final goal. The ground realities need to change, which is yet to take place. Most importantly, the Department of Obstetrics and Gynecology in the country need to develop infrastructure and human resources to address the fluoride issues as the nonnutritional factor effectively. The nutritional intervention to follow does not involve major inputs as it is being practiced in ANCs hospitals and schools.

The investigations were performed in three different sets of individuals using the same protocol and guidelines. The investigated subjects were: pregnant women; adolescent girls; boys and girls. The methodology, exclusion and inclusion criteria, and results are reported separately for each of the three sets of individuals investigated with interventions practiced for clarity.

\section{Materials and Methods}

\section{Pregnant Women}

Two government hospitals in the national capital territory were chosen, one from west and the other from east of Delhi. The hospital administration and the obstetrician and gynecologist of the hospitals were explained the procedure and protocol. They participated in the program. ANC approach was preferred, as the investigations could be performed and monitored until delivery.

\section{Exclusion and Inclusion Criteria}

- Pregnant women more than 20 weeks of gestation and those suffering from diabetes, tuberculosis, bleeding during pregnancy, high blood pressure (BP), HIV AIDS, 
malaria, and other health problems were excluded. Only those who were in first or second trimester and anemic $(\mathrm{Hb}<9.0 \mathrm{~g} / \mathrm{dL} ; \mathrm{Hb}<11.0 \mathrm{~g} / \mathrm{dL})$ were considered for investigations. There were 3,262 pregnant women who were screened for participating in the program.

- The sample and control groups' women were identified through a computerized random sampling procedure. The investigations in sample and control groups were three laboratory tests (1) $\mathrm{Hb}$ test, (2) $\mathrm{F}^{-}$content in drinking water, and (3) $\mathrm{F}^{-}$content in urine sample. Hb tested by HemoCue 201+ which is extensively used for field studies. $\mathrm{F}^{-}$was estimated in water and urine using ion meter with $\mathrm{F}^{-}$-specific electrode. ${ }^{23}$ The sample and control groups women consumed iron and folic acid tablets provided by the hospital. Hospital also provided diet counseling. The Fluorosis Research and Rural Development Foundation ensured that they ate nutritive diet with fruits, vegetables, and dairy products and avoided the street foods, snacks, and churans containing rock salt with high fluoride. Height and weight measurements were made and BP measurements from hospital records were transferred to the study format.

\section{Interventions Practiced}

- Diet editing was provided to avoid consumption of fluoride containing food, water, and other substances for arresting injury to GI mucosa. If fluoride in water has $>1.0 \mathrm{mg} / \mathrm{L}$, the family was shifted to a safe source available in the nearby locality. If urine fluoride was high $>1.0 \mathrm{mg} / \mathrm{L}$, information on diet and dietary habits traced to identify the source of fluoride and advised against its consumption and possible adverse effects explained.

- Diet counseling was introduced to promote intake of nutritive diet. They were also given printed information on dietary regime to follow. The information benefited other members of the family and was not pregnancy specific.

The control group was not included for providing interventions. The pregnant women were advised to attend ANCs, once in every month. Some did and some came after longer interval. On every visit, the women were tested for $\mathrm{Hb}$ and urine $\mathrm{F}^{-}$. They were also advised delivery in the same hospital, but some went to their mother's house for delivery, and some delivered in a nearby hospital as per their convenience. Prior to analyzing the data as per the protocol and guidelines, it was decided among those women who attended ANCs minimum of three visits were only be considered for evaluation. The contact period through maximum seven visits to ANC among sample group was 120 days and in control group, 111 days. The body mass index (BMI) was calculated during the first visit and the last visit prior to delivery. The delivery details and birth weight of the infants were recorded from the labor room register. This is to state that Prof. (Dr.) Kamla Ganesh, director, professor of Department of Obstetrics and Gynecology, Maulana Azad Medical College was the consultant obstetrician who designed the protocol and guidelines for the study. The total numbers of women who followed the guidelines in sample and control groups were 481 . The sample group had
234 and control group had 247 pregnant women. The results presented are from the two groups.

\section{School Children}

Anemia in school children was dealt with (1) adolescent girls in one school and (2) boys and girls in six schools. The protocol drawn up was slightly different although aimed at assessing the drinking water fluoride, UFLs, and $\mathrm{Hb}$. The impact of two interventions diet editing and diet counseling was followed up at three intervals $(1,3$, and 6 months) postintervention.

\section{Adolescent Girls}

Adolescent girls 10 to 17 years of age studying in classes VI to $\mathrm{X}$ at a Government Senior Secondary School were eligible and enrolled in the study ( $n=943)$. The investigating team addressed the school administration and teachers and how anemia can be corrected with simple dietary interventions. When the school was interested to improve the health of the students, the principal and parents completed the "informed consent document" as well as the "ascent" of the children to commence the study. The school dewormed the children at the school's expense and provided a classwise list of dewormed students. Urine sample from girls during menstrual period was not collected.

The three tests done were (1) $\mathrm{Hb}$ for screening the number of anemic students, (2) drinking water $\mathrm{F}^{-}$, and (3) urine fluoride. Besides, nutritional education which included diet editing followed by diet counseling was imparted to mothers of students in groups in the presence of their wards and teachers during parent-teacher meeting (PTM). A little pictorial booklet on different recipes for breakfast, lunch, and dinner was provided for better understanding of the information imparted on completing the baseline investigations. It was also designed to know the impact of intervention at first, third, and sixth months postintervention.

\section{Boys and Girls}

Students from six schools were also included ( $n=2,420)$. In investigating school children, four schools were grouped under sample and two schools under control group. The protocol involved testing drinking water both in sample and control schools for fluoride content. The urine fluoride was tested besides $\mathrm{Hb}$. The sample school children provided diet editing and counseling during PTMs and followed up the impact at first, third, and sixth months postinterventions. The control group children were provided diet counseling but not diet editing. The results are reported on $\mathrm{Hb}$ in the children in sample and control schools.

\section{Results and Discussion}

\section{In Pregnant Women}

The studies focusing on correction of anemia in pregnancy commenced with focus on fluoride withdrawal from consumption cum use. The concept that $\mathrm{F}^{-}$is good for teeth misguided the entire nation. The concept is proven to be unscientific and unethical since decades. In view of the earlier facts, the U.S. Department of Health and Human Services 
Federal Panel on Community Water Fluoridation has made a final recommendation on community water fluoridation that replaces the relevant parts of the 1962 Drinking Water Standards. Although the earlier recommendation, based on the outdoor air temperature of geographic regions involved a range of 0.7 to $1.2 \mathrm{mg} \mathrm{F}^{-} / \mathrm{L}$, the new recommendation, for community water systems that currently fluoridate or plan to do so, is for a level of $0.7 \mathrm{mg} \mathrm{F}^{-} / \mathrm{L}^{24}$

The results obtained from investigating 234 sample group and 237 control group pregnant women are reported after appropriate statistical analysis. The results have been published. ${ }^{25-27}$ The results published reveal:

- The Hb improved in sample group women from 5.6 to $14.0 \mathrm{~g} / \mathrm{dL}$ in $77 \%$ of pregnant women prior to delivery.

- The UFL reduced in $65 \%$ in pregnant women in sample group prior to delivery.

- Preterm deliveries (<34 weeks' gestation) reduced to $1 \%$ in sample group in contrast to $5 \%$ in control group.

- Term deliveries (34-37 weeks' gestation) reduced to $27 \%$ in sample group in contrast to $32 \%$ in the control group.

- Full-term delivery ( $\geq 37$ weeks' gestation) enhanced to $72 \%$ in sample group in contrast to $63 \%$ in the control group.

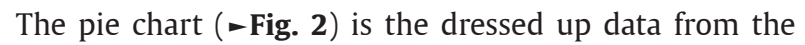
sample group ( $n=234)$ and control group $(n=247)$.

The pie chart on pregnant women delivering normal birth weight infants $(2.5-3.89 \mathrm{~kg})$ achieved $83 \%$ in sample group, reducing low birth weight infants $(1.8-2.48 \mathrm{~kg})$ to $17 \%$, whereas in control group, the normal birth weight infants were only $59 \%$ and low birth weight infants reached to $41 \%$. This is the first time the nation has achieved such valuable outcome following withdrawal of a toxin from ingestion.

Scientists/obstetricians in the past made efforts to inject iron sucrose..$^{28,29}$ The Federation of Obstetricians and Gynecologists of India (FOGSI) had tried to bypass the GI route by two to three injections of iron-sucrose complex through intravenous/intramuscular route to correct anemia and it worked (personal communication with president, FOGSI, 2010). They made a proposal and submitted to the government for adopting the new route for iron administration. But it did not meet with the approval of World Health Organization as announced by a senior official of the Ministry of Health and Family Welfare during the Global Maternal Health Conference, organized by Bill \& Melinda Gates Foundation; Engender, United States; and Public Health Foundation of India held in New Delhi during September 2010.

When advised administration of iron and folic acid, the pregnant women may or may not accept the treatment. There is a yet another serious drawback that the growing fetus needs a variety of other nutrients, besides iron and folic acid for developing into a normal healthy infant. However, it was amply evident that there are problems in absorption of iron and folic acid besides other nutrients in the diet due to serious structural derangements in the GI tract due to several reasons including the abnormally high amount of fluorides in drinking water and food. As reported in the introduction, the observations made due to $\mathrm{F}^{-}$toxicity due to drinking water and food with high fluoride contents were loss of microvilli, loss of mucus production, and denatured mucosal surface with extensive cracked

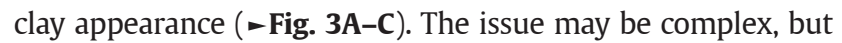
demands probing into, in the interest of maternal and infant health in India. What are the flows and how it was caused by fluoride? What does fluoride do to the body?

1. Decreases production of red blood cells (RBCs) by bone marrow and other hemopoietic tissues and increases erythrocyte abnormalities resulting in premature death of RBCs. Owing to $\mathrm{F}^{-}$-induced thyroid hormone deficiency, an adequate stimulus was lacking for RBC production.

2. Reduces blood folic acid activities.

\section{Sample Group \\ $(n=234)$}

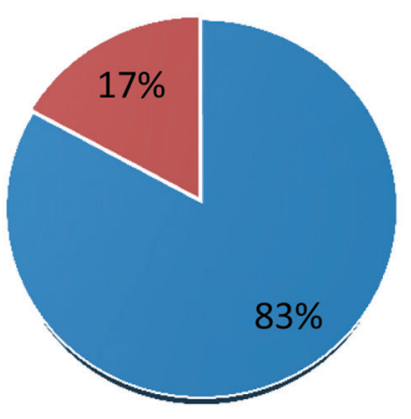

- NBW - LBW
Control Group $(n=247)$

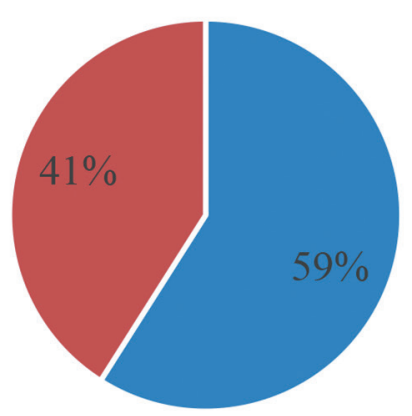

- NBW - LBW

Fig. 2 Showing pie charts of sample and control groups, where the normal birth weight infants born to healthy nonanemic mothers are $83 \%$ reducing low birth weight infants to $17 \%$ compared with the control group. Sample group: Provided (1) diet editing and (2) diet counseling, besides iron and folic acid supplementation. Control group: Provided (1) diet counseling only and (2) no diet editing. Iron and folic acid supplemented. LBW, low birth weight $(<2.5 \mathrm{~kg})$; NBW, normal birth weight $(>2.5 \mathrm{~kg})$. 


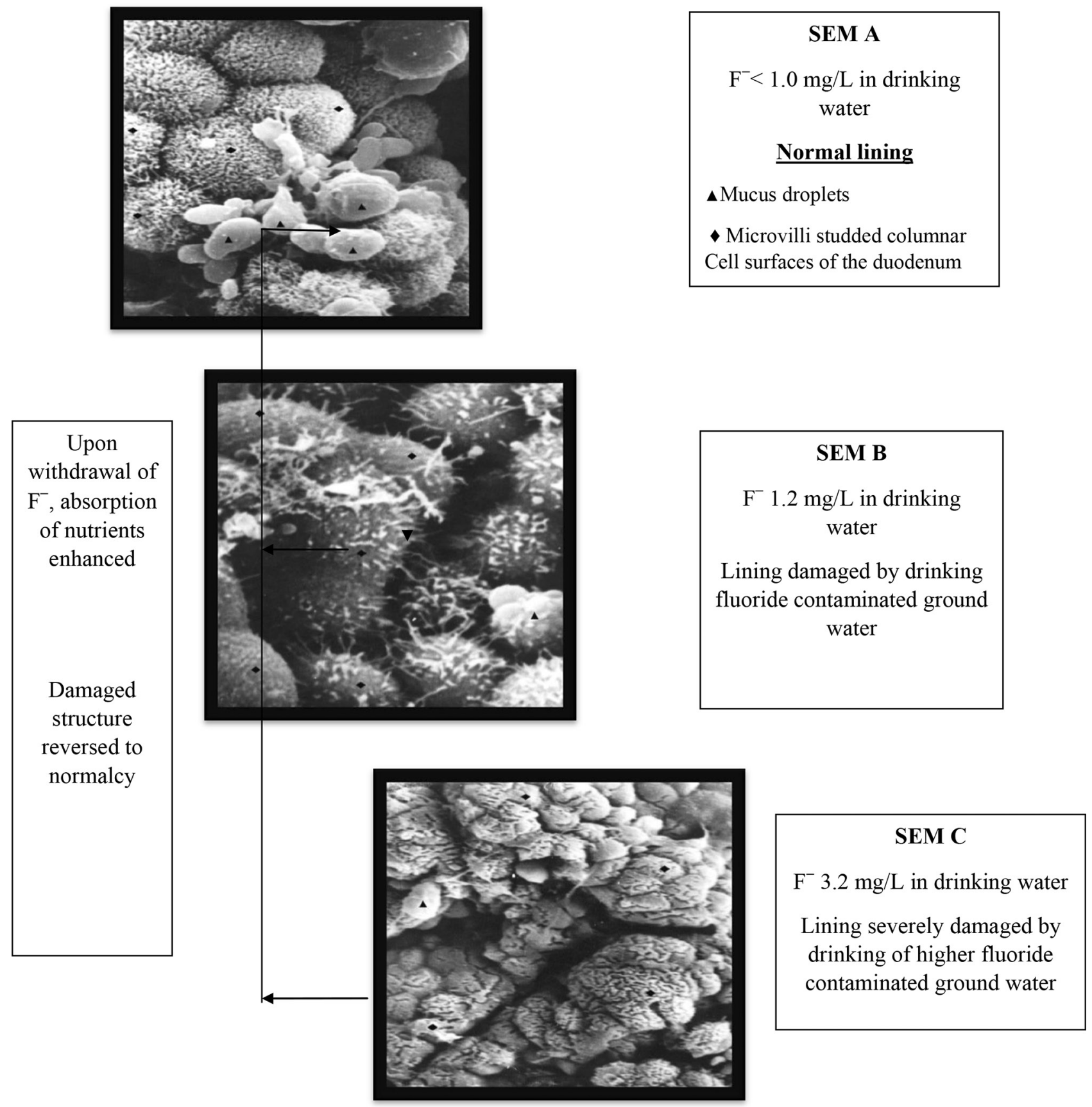

Fig. 3 Three scanning electron micrographs (SEM A-C) showing the normal mucosa (SEM A) and damaged gastrointestinal mucosa with loss of microvilli, loss of mucus droplets, and cracked clay appearance (SEM B and C) occurring due to drinking of higher fluoride contaminated ground water. Upon withdrawal of $\mathrm{F}^{-}$within a few days the mucosa regenerated and absorbed nutrients and $\mathrm{Hb}$ enhanced.

3. Diminishes beneficial microbial growth in the gut and inhibits production of vitally needed vitamin $B_{12}$.

4. Causes loss of microvilli (brush border) in the intestinal lining resulting in poor absorption of nutrients critical for the biosynthesis of $\mathrm{Hb}$.

If the fluoride levels in drinking water are high, then they were diverted to safe drinking water $\left(\mathrm{F}^{-} \leq 1.0 \mathrm{mg} / \mathrm{L}\right)$.

In spite of consuming safe water, fluoride high in urine and low $\mathrm{Hb}$ were introduced to diet editing and diet counseling during the visits to ANCs to eliminate fluoride consumption through food and habit forming substances namely churans and promote nutrients intake.
The maternal health program needs changes in policy for "obstetric practice" by way of introducing a few additional tests, and monitoring the pregnant women during regular ANC visits until delivery. The solution for correcting preventable maternal mortality has been field tested for 15 years and results made available through publications in reputed journals. Withdrawal of fluoride from consumption and use can be designated as a "masterstroke" as the damages inflicted in a body can be reversed. Hb production improved leading to better health among the poor and rich, rural and urban, and educated and uneducated pregnant women. The BMI also revealed positive changes ( - Table $\mathbf{1}$ ). 
To end anemia in pregnancy and promote maternal and infant health, it should not take long time for the nation to achieve "Anemia Mukt Bharat." India, undoubtedly would lead the nations across the globe with the novel idea in combating the problem which the nation was involved for four decades. It is one of the simplest solutions presently known to exist. The protocol developed should set matters right and accept the verdict that fluoride is a major factor causing the damages in lowering $\mathrm{Hb}$ production and its withdrawal is promoting improved $\mathrm{Hb}$ and correction of anemia in all sections of the society. There is no shortcut for improving $\mathrm{Hb}$ in pregnancy and birth weight of infants than promoting safe water and nontoxic food for consumption with IFS. India need not be waiting until 2030 to attain the results of SDGs, to correct anemia. This communication is for delivering justice to pregnant women and infants in the nation at the earliest.

\section{In School Children}

\section{Adolescent Girls}

In one school with 943 students, anemia ( $\mathrm{Hb}<12.0 \mathrm{~g} / \mathrm{dL})$ prevalence was $57 \%$. UFL $>1.0 \mathrm{mg} / \mathrm{L}$ was prevalent in $56 \%$ of students. Of 250 adolescent girls who were anemic with high UFL with parent's consent, $88 \%$ of girls participated in the study. The drinking water fluoride was safe and ranged from 0.114 to $0.88 \mathrm{mg} / \mathrm{L}$ in the school and homes. The baseline study revealed severe anemia $(<7.0 \mathrm{~g} / \mathrm{dL})$ in $3 \%$ students, moderate and mild anemia $(7.0-12.0 \mathrm{~g} / \mathrm{dL})$ in $97 \%$, and nonanemic (> $12.0 \mathrm{~g} / \mathrm{dL}$ ) were $0 \%$ among the 250 participated in the program. Tests were repeated, that is, Hb \& UFL in 1, 3 and 6 months postinterventions.
In 1, 3, and 6 months postintervention, 162, 240, and 244 students from 250 were participated. Holidays, festivals, and menstrual period led to the absence of a few students for impact assessment.

The most interesting observation was that anemic students in 1, 3, and 6 months reduced significantly, whereas in nonanemic category $(>12.0 \mathrm{~g} / \mathrm{dL}$ ) which was nearly $0 \%$ at baseline survey increased by $20 \%$ by 1 month, $31 \%$ by 3 months, and $41 \%$ by 6 months postintervention. These were statistically significant at $p$-value $<0.0001$. Hb ranged from 12.1 to $13.3,12.1$ to 14.0 , and 12.1 to $14.4 \mathrm{~g} / \mathrm{dL}$, respectively, during 1,3 , and 6 months compared with baseline data. The approach adopted with adolescent girls, educating the mothers paid dividend and interventions practiced would also help ensuring, beneficial by preventing transgenerational anemia, that is, adolescent girls getting married at a young age and producing anemic infants. ${ }^{30}$

\section{Boys and Girls in Six Schools}

As the highly destructive fluoride enters the body with a variety of sources besides drinking water, destroys the lining of intestine and prevents absorption of nutrients. The study was conducted in 2,420 school children from six schools studying in classes VI to X. The basic information collected is reported in - Table 2.

Prevalence of anemia in boys and girls, $\mathrm{Hb}$ in sample and control groups at baseline is reported in $\mathbf{- T a b l e s} \mathbf{3}$ and $\mathbf{4}$.

All students participated in baseline screening for $\mathrm{Hb}$ but not for postintervention assessment due to vacation, festivals, and personal reasons.

$\mathrm{Hb}$ levels enhanced during 1,3 , and 6 months postintervention and results are reported in $\boldsymbol{-}$ Table $\mathbf{5}$.

Table 1 The impact of interventions on the BMI of the pregnant women of sample and control groups

\begin{tabular}{|l|l|l|l|}
\hline Groups of pregnant women & BMI & BMI-initial (\%) & BMI-prior to delivery (\%) \\
\hline \multirow{2}{*}{$\begin{array}{l}\text { Sample } \\
n=234\end{array}$} & $<18.5$ (undernourished) & 22 & 1 \\
\cline { 2 - 4 } & $25.0-29.9$ (desirable in pregnancy) & 3 & 31 \\
\hline \multirow{2}{*}{\begin{tabular}{l} 
Control $n=247$ \\
\cline { 2 - 4 }
\end{tabular}} & $<18.5$ (undernourished) & 27 & 2 \\
\cline { 2 - 4 } & $25.0-29.9$ (desirable in pregnancy) & 5 & 14 \\
\hline
\end{tabular}

Abbreviation: BMI, body mass index.

Table 2 Study design

\begin{tabular}{|l|l|l|}
\hline Total students $=2,420$ & Sample schools, $\boldsymbol{n}=\mathbf{4}$ & Control schools, $\boldsymbol{n}=\mathbf{2}$ \\
\hline Total students screened for Hb and found anemic & $907 / 1,815$ & $345 / 605$ \\
\hline$<12.0 \mathrm{~g} / \mathrm{dL}$ & $50 \%$ & $57 \%$ \\
\hline Anemic students with high urine fluoride level & $479 / 860^{\mathrm{a}}$ & $225 / 326^{\mathrm{a}}$ \\
\hline$>1.0 \mathrm{mg} / \mathrm{L}$ & $55.7 \%$ & $69.0 \%$ \\
\hline $\begin{array}{l}\text { Drinking water samples } 410 \text { and } 214 \text { from home and school respectively } \\
\text { tested for F }\end{array}$ & $410 / 479^{\mathrm{b}}$ & $214 / 225^{\mathrm{b}}$ \\
\hline Percentage samples tested & $85.6 \%$ & $95 \%$ \\
\hline All samples safe with reference to $\mathrm{F}^{-}(\mathrm{mg} / \mathrm{L})$ & $0.114-0.873 \mathrm{mg} / \mathrm{L}$ & $0.014-0.985 \mathrm{mg} / \mathrm{L}$ \\
\hline
\end{tabular}

Source: Susheela et al. ${ }^{31}$

Abbreviation: $\mathrm{Hb}$, hemoglobin.

a Urine sample of girl students during menstrual period not collected.

'Many families were sharing public water sources (viz., hand pump, tube well, and municipal supply). Schools had either one or two sources of water for consumption. 
Table 3 Prevalence of anemia in boys and girls among the students of six schools

\begin{tabular}{|l|l|l|l|}
\hline & $\begin{array}{l}\text { Total students screened for } \\
\text { anemia }(\boldsymbol{n = 2 , 4 2 0 )}\end{array}$ & $\begin{array}{l}\text { Total number of boys } \\
(\boldsymbol{n}=\mathbf{8 7 6})\end{array}$ & $\begin{array}{l}\text { Total number of girls } \\
(\boldsymbol{n}=\mathbf{1 , 5 4 4 )}\end{array}$ \\
\hline Prevalence of anemia (\%) & 50.3 & 38.6 & 56.9 \\
\hline Prevalence of anemia range (\%) & $37-63$ & $30-56$ & $48-69$ \\
\hline
\end{tabular}

Source: Susheela et al. ${ }^{31}$

Table $4 \mathrm{Hb}$ levels $(\mathrm{g} / \mathrm{dL})$ of the sample and control student groups at baseline

\begin{tabular}{|l|l|}
\hline Group & Hb level $(\mathrm{g} / \mathrm{dL})$ \\
\hline Sample $^{\mathrm{a}}(n=445)$ & $11.1 \pm 1.1^{\mathrm{b}}(5.8-12.0)^{\mathrm{c}}$ \\
\hline Control $(n=225)^{\mathrm{c}}\left(11.2 \pm 1.1^{\mathrm{b}}(7.0-12.0)^{\mathrm{c}}\right.$ \\
\hline
\end{tabular}

Source: Susheela et al. ${ }^{31}$

Abbreviation: $\mathrm{Hb}$, hemoglobin.

${ }^{\text {a Among the }} 479$ anemic students reported, only 445 participated as 34 students were absent on the day of assessment. Statistical test applied: analysis of variance.

bMean \pm standard deviation.

'The range of $\mathrm{Hb}$.

In - Table 6, it is evident that $\mathrm{Hb}$ during interventions among the students in moderate and mild category, reduced from 70 to 64 to $53 \%$ in 1, 3, and 6 months, respectively. As a result, the students in nonanemic category, which was $0 \%$ during baseline study, increased from 29.5 to 35.8 to $45 \%$, respectively, during 1,3 , and 6 months postinterventions. These are significant positive changes taken place in improving the well-being of the students through diet, upon withdrawal of fluoride. Iron and folic acid supplements to school children are not required if the mothers/parents are adequately informed how to improve nutritive value of the diet, that is, the three major meals they serve: breakfast, lunch, and dinner. Wayside junk food consumption ought to be stopped.

The impact of interventions practiced among the adolescent girls in one school and boys and girls in six schools has commonality. In adolescent girls, the impact of interventions practiced at 1,3 , and 6 months raised the $\mathrm{Hb}$ among the category (> $12.0 \mathrm{~g} / \mathrm{dL}$ ) from 0 to 20,31 , and $41 \%$, respectively, whereas in boys and girls in six schools, upon practice of interventions at three intervals, the rise in $\mathrm{Hb}$ in $>12.0 \mathrm{~g} / \mathrm{dL}$ category recorded are $29.5,35.8$, and $45.3 \%$, respectively. ${ }^{31}$ These observations are conveying important take home messages to the WIFS program "ON" in schools across the country.

In conclusion, this article in Annals of the National Academy of Medical Sciences (India) would provide an opportunity for senior medical professionals/fellows of the academy to pave the way to provide appropriate science and technology-based advice to policy makers in the government to set matters right. The nation has waited for 40 long years to reach out to this stage of development through scientific and technical inputs.

- India is known for low $\mathrm{Hb}$ and anemia in pregnant women in all sections of the society whether they belong to rural/urban, uneducated/educated, and poor/rich families. Anemia has plagued the nation for almost four decades.

- Anemia can be due to many reasons: poor nutrition, urinary tract infection, parasitic infestation, and/or periodontitis/gingivitis (inflammation and bleeding from gums). Besides affliction of malaria, hemoglobinopathies (sickle cell anemia, thalassemia) when RBCs are not produced adequately can cause anemia.

- However, iron deficiency anemia is very common afflicting millions of women in India/worldwide. Government of India recognizing the severity of the problem of anemia in pregnancy as early as 1970 and since then IFS was initiated as a part of antenatal care throughout the country. But the hope for benefits was not forthcoming.

- The MDGs 5 and 4 (to reduce maternal and infant mortality) could not be achieved by the nation until 2015 . The policy makers in the government were advised, though a notion prevails that women do not consume the iron + folic acid tablets provided free of cost by the government. The numbers of tablets to be provided are 90 or 100 . But some obstetricians even provided the tablets until delivery when they found the women were from very poor background. The number of tablets consumed and the maximum tablets in a pouch, during every visit to ANC have been counted. The women do take the tablets.

- In the recent past, accredited social health activists and auxiliary nurse midwife are also associated with the

Table 5 Hb levels ( $\mathrm{g} / \mathrm{dL}$ ) at 1, 3, and 6 months postintervention

\begin{tabular}{|l|l|l|l|}
\hline Group & $\mathbf{1}$ mo & 3 mo & 6 mo \\
\hline Sample $(n=445)$ & $11.3 \pm 1.2^{\mathrm{a}}$ & $11.5 \pm 1.2^{\mathrm{a}}$ & $11.7 \pm 1.4^{\mathrm{a}}$ \\
& $5.8-13.5^{\mathrm{b}}$ & $6.8-14.2^{\mathrm{b}}$ & $5.7-14.7^{\mathrm{b}}$ \\
\hline Control $(n=225)$ & $11.2 \pm 1.1^{\mathrm{a}}$ & $11.5 \pm 1.1^{\mathrm{a}}$ & $11.3 \pm 1.2^{\mathrm{a}}$ \\
& $7.0-13.1^{\mathrm{b}}$ & $6.1-14.0^{\mathrm{b}}$ & $6.1-14.2^{\mathrm{b}}$ \\
\hline
\end{tabular}

Source: Susheela et al. ${ }^{31}$

Abbreviation: $\mathrm{Hb}$, hemoglobin.

Note: $p$-Value significant at $<0.0001$ for sample group and $p$-value $<0.02$ for control group.

${ }^{a}$ Mean \pm standard deviation.

bHb range. 
Table $6 \mathrm{Hb}(\mathrm{g} / \mathrm{dL})$ analysis (categorywise)

\begin{tabular}{|c|l|l|l|l|}
\hline Time period & Group & $\begin{array}{l}\text { Nonanemic } \\
(>12.0 \mathrm{~g} / \mathrm{dL})\end{array}$ & $\begin{array}{l}\text { Moderate and mild } \\
(\mathbf{7 . 0}-12.0 \mathrm{~g} / \mathrm{dL})\end{array}$ & Severe (<7.0 g/dL) \\
\hline \multirow{2}{*}{ At baseline } & Sample $(n=445)$ & $0 \%$ & $436(98 \%)$ & $9(2.0 \%)$ \\
\cline { 2 - 5 } & Control $(n=225)$ & $0 \%$ & $224(99.6 \%)$ & $1(0.4 \%)$ \\
\hline Postintervention & Sample $(n=339)$ & $\mathbf{1 0 0 ( 2 9 . 5 \% )}$ & $\mathbf{2 3 8 ( 7 0 . 2 \% )}$ & $1(0.3 \%)^{\mathrm{a}}$ \\
\hline \multirow{2}{*}{$1 \mathrm{mo}$} & Control $(n=204)$ & $34(16.7 \%)$ & $170(83.3 \%)$ & $1(0.2 \%)^{\mathrm{b}}$ \\
\hline \multirow{2}{*}{$3 \mathrm{mo}$} & Sample $(n=408)$ & $\mathbf{1 4 6 ( 3 5 . 8 \% )}$ & $\mathbf{2 6 1 ( 6 4 . 0 \% )}$ & $1(0.6 \%)^{\mathrm{b}}$ \\
\cline { 2 - 5 } & Control $(n=164)$ & $30(20.7 \%)$ & $129(78.7 \%)$ & $6(1.5 \%)^{\mathrm{c}}$ \\
\hline \multirow{2}{*}{$6 \mathrm{mo}$} & Sample $(n=397)$ & $\mathbf{1 8 0 ( 4 5 . 3 \% )}$ & $\mathbf{2 1 1 ( 5 3 . 2 \% )}$ & $0(0 \%)^{\mathrm{c}}$ \\
\cline { 2 - 5 } & Control $(n=157)$ & $40(26.1 \%)$ & $113(73.9 \%)$ & \\
\hline
\end{tabular}

Source: Susheela et al. ${ }^{31}$

Abbreviation: $\mathrm{Hb}$, hemoglobin.

${ }^{a} p$-Value $<0.003$ (significant).

${ }^{\mathrm{b}} \mathrm{p}$-Value $<0.002$ (significant).

${ }^{c} p$-Value $<0.0001$ (significant).

program to educate pregnant women and inform the merits of hospital delivery so that they have a healthy infant born.

In a recent report of the government (NITI Aayog, 2019) appeared in Indian Express on November 9, 2019, MMR in various Indian states have been reported. The MMR measured as the number of maternal deaths per lakh $(100,000)$ live births varies among the Indian states for a high of 229 per lakh in Assam (one of the northeastern states). This emerged out of the data published in a Special Bulletin on Maternal Mortality in India 2015 to 2017 of the Sample Registration System. In this context, it is stated that Assam is one of the severely endemic states for fluorosis with ground water contamination of fluoride to the extent of $23.0 \mathrm{mg} / \mathrm{L}$. The other states with high MMR 2015 to 2017 are: Uttar Pradesh $=216$, Madhya Pradesh $=188$, Rajasthan $=186$, Odisha $=168$, Bihar $=165$, and Chhattisgarh $=141$.

A senior obstetrician in the "Janani Hospital, Jaipur," said she has never seen normal birth weight infants in that hospital for years." The situation is as bad as that.

Dr. Sunita Mittal, an eminent obstetrics and gynecology practitioner, in a review article in Annals of the National Academy of Medical Sciences (India), 201932 has focused on ill effects of smoking and tobacco chewing on Reproductive, Maternal, Newborn, Child health, and Adolescent program. But anemia in pregnancy leading to maternal mortality and infant mortality and low birth weight infants is not the main focus. Besides, smoking and tobacco chewing and its reflection on pregnancy outcome are explained and are informative.

Dr. Prema Ramachandran, the former health advisor to the Planning Commission, a well-known medical scientist and obstetrician, has also contributed an article "Time trends in prevalence of anemia in preschool children in India" in Annals of the National Academy of Medical Sciences (India), 2019 ${ }^{33}$ She also highlighted it is a major public health problem in Indian children. India introduced iron and folic acid supplementation for preschool children in 1970s. After 20 years, in 1990, the component for detection and treatment was added. She has indicated on the importance of the program to assess the impact of the program in preschool children. She concluded, by indicating some improvement in $\mathrm{Hb}$ in preschool children in the last decade. But prevalence of anemia continues to be very high.

However, this communication" is focusing on anemia due to a highly toxic chemical $\mathrm{F}$, which has three dreadful destructive activities: (1) hormone disruptor, (2) enzyme inhibitor, and (3) neurotoxin. All these are contributing in causing anemia in all sections of the society.

The "Anemia Mukt Bharat" slogan of the Government of India has highlighted that "Anemia Affects All."

- Children (58\%)-124 million (5-59 months) and 134 million (5-9 years)

- Girls (54\%) and boys (29\%)-115 million (10-19 years)

- Women of reproductive age (53\%)-17 million (20-24 years)

- Pregnant women (50\%)-30 million

- Lactating women (58\%)-27 million.

With the earlier background information, the nation needs to move forward swiftly with a simple practical protocol to achieve high $\mathrm{Hb}$ and correct anemia in pregnancy, children, and all others. The beneficiary effects would lead the nation to social and economic development. A recent report has supported the inferences drawn in this article that "when pregnant women consumed fluoride are unable to absorb iron and other supplements that are provided in ANCs resulting into becoming anemic and deliver small infants or risking their lives." ${ }^{34}$

It should be made mandatory that all OBGY departments in hospitals across the country should introduce the simple and practical protocol brought out in this article for the improvement of maternal and newborn health.

In a similar manner, the protocol for improving $\mathrm{Hb}$ should be introduced in all schools across the country with diet editing and diet counseling imparted to parents/mothers during PTMs. The nation should not delay implementation of the program. The year 2020 should be the beginning of a new era. 


\section{Conflict of Interest}

None declared.

\section{Acknowledgments}

Department of Science and Technology, Ministry of Science and Technology; Department of Health Research, Ministry of Health and Family Welfare; and the Indian Council of Medical Research (ICMR) are acknowledged for the funds provided in the years 2011 to 2013. Doctoral students, research associates, and scientists who worked with A.K.S. at AIIMS, New Delhi and the Fluorosis Research and Rural Development Foundation of India acknowledged for contributing in the understanding of fluoride action and fluorosis to a great extent. The authors are grateful to the consultants and scientists especially Ms. Santha Nair for contributing through their inputs during the discussion and preparation of the manuscript.

\section{References}

1 Ministry of Health and Family Welfare. Government of India. Prophylaxis against nutritional anaemia among mothers and children. Technical information MCH No. 1.p3, 1970

2 Evaluation of National Nutritional Anemia Prophylaxis programme, Report of Task Force study Indian Council of Medical Research (ICMR), New Delhi; 1989

3 Field supplementation trial in pregnant women with 60,120 and $180 \mathrm{mg}$ of iron and $500 \mu \mathrm{g}$ of folic acid. Report of a Task Force study. Indian Council of Medical Research (ICMR), New Delhi, 1992

4 UNICEF, State of the art report on the extent of fluoride in drinking water and the resulting endemicity in India. Report by Fluorosis Research and Rural Development Foundation for UNICEF, New Delhi; 1999

5 Venkateshwara Rao K, Mahajan CL. Fluoride content of some common south Indian foods and their contribution to fluorosis. J Sci Food Agric 1991;51:275-279

6 Nanda RS. Fluoride content of North Indian foods. Indian J Med Res 1972;60(10):1470-1482

7 Izuora K, Twombly JG, Whitford GM, Demertzis J, Pacifici R, Whyte MP. Skeletal fluorosis from brewed tea.J Clin Endocrinol Metab 2011;96(8):2318-2324

8 Whyte MP, Totty WG, Lim VT, Whitford GM. Skeletal fluorosis from instant tea. J Bone Miner Res 2008;23(5):759-769

9 Fein NJ, Cerklewski FL. Fluoride content of foods made with mechanically separated chicken. J Agric Food Chem 2001;49(9):4284-4286

10 Susheela AK, Fluorosis Mitigation: Guidelines for Program Execution for Policy Makers, Health Administrators and Doctors. Chap. 1. New Delhi: Fluorosis Research and Rural Development Foundation; 2015 7-9

11 Susheela AK, A Treatise on Fluorosis. Revised 3rd ed. New Delhi: Fluorosis Research and Rural Development Foundation; 2007

12 Susheela AK, Jain SK. Erythrocyte membrane abnormality and echinocyte formation. Proceedings of the 14th Conference of the International Society for Fluoride Research, Japan. Elsevier Publishing House, Amsterdam, 1986:231-239

13 Susheela AK, Kumar A, Bhatnagar M, Bahadur R. Prevalence of endemic fluorosis with gastro-intestinal manifestations in people living in some North-Indian villages. Fluoride 1993;26(2):97-104
14 Susheela AK, Das TK, Gupta IP, et al. Fluoride ingestion and its correlation with gastro-intestinal discomfort. Fluoride 1992;25(1):5-22

15 Das TK, Susheela AK, Gupta IP, Dasarathy S, Tandon RK. Toxic effects of chronic fluoride ingestion on the upper gastrointestinal tract. J Clin Gastroenterol 1994;18(3):194-199

16 Dasarathy S, Das TK, Gupta IP, Susheela AK, Tandon RK. Gastroduodenal manifestations in patients with skeletal fluorosis. J Gastroenterol 1996;31(3):333-337

17 Gupta IP, Das TK, Susheela AK, Dasarathy S, Tandon RK. Alimentary tract and pancreas: fluoride as possible etiological factor in non-ulcer dyspepsia. J Gastroenterol Hepatol 1992;7:355-359

18 Susheela AK, Bhatnagar M. Reversal of fluoride induced cell injury through elimination of fluoride and consumption of diet rich in essential nutrients and antioxidants. Mol Cell Biochem 2002;234-235(1-2):335-340

19 Susheela AK, Mondal NK, Tripathi N, Gupta R. Early diagnosis and complete recovery from fluorosis through practice of interventions. J Assoc Physicians India 2014;62(7):572-579

20 Susheela AK, Mondal NK, Rashmi G, Ganesh K. Rectification of anaemia in pregnancy. In: Proceedings of the Convention International Forum on Quality and Safety in Health Care, Asia, BMJ Event, Hong Kong, 2015, Poster No. 215

21 Susheela AK. To empower population for nutritional requirements through diet for better health. In: Proceedings of the International Forum on Quality and Safety in Health Care, Asia. BMJ Event, Singapore, 2016. Poster No. 5 in the session Population and Public Health

22 Analytical test report. Black rock salt. Tested and reported by sophisticated Instrumentation centre for applied research and testing (SICART) Department of Science and Technology, Govt. of India, New Delhi. Sardar Patel Centre for Science and Technology, Charutar Vidya Mandal, Vallabh Vidyanagar, Anand, Gujarat, India. 2008. Available at: http://sicart.res.in. Accessed January 10, 2018

23 Hall LL, Smith FA, De Lopez OH, Gardner DE. Direct potentiometric determination of total ionic fluoride in biological fluids. Clin Chem 1972;18(12):1455-1458

24 Centers for Disease Control and Prevention. Community Water fluoridation. Available at: http://www.cdc.gov/fluoridation/. Updated April 24, 2015; cited May 14, 2015

25 Susheela AK, Mondal NK, Gupta R, et al. Effective interventional approach to control anaemia in pregnant women. Curr Sci 2010;98:320-330

26 Susheela AK. Anemia in pregnancy: an easily rectifiable problem guest editorial. Fluoride 2010;43(2):104-107

27 Susheela AK, Control of anaemia in pregnancy, pre-term deliveries, low birth weight babies in natural conception and the possibility in assisted reproduction. In: Raghunathan P, Susheela AK, Mehta RH, eds. Assisted Reproduction Technologies (ART) - Dr. T.C. Anand Kumar Memorial Volume; 2013 263-278

28 al-Momen AK, al-Meshari A, al-Nuaim L, et al. Intravenous iron sucrose complex in the treatment of iron deficiency anemia during pregnancy. Eur J Obstet Gynecol Reprod Biol 1996;69(2):121-124

29 Danielson B, Intravenous iron therapy-efficacy and safety of iron source. In: Breymann C, ed. Prevention and Management of Anaemia in Pregnancy and Postpartum Haemorrhage. Zurich, Switzerland: Schellenberg Druck AG; 1998:93-106

30 Susheela AK, Gupta R, Mondal NK. Anaemia in adolescent girls: an intervention of diet editing and counselling. Natl Med J India 2016;29(4):200-204 
31 Susheela AK, Mondal NK, Gupta R, Sethi M, Pandey RM. Fluorosis is linked to anaemia. Curr Sci 2018;115(4):692-700

32 Mittal S. Smoking and tobacco use: ill effects on reproductive, maternal, newborn, child health, and adolescent (RMNCHA) program - a review. Ann Natl Acad Med Sci (India) 2019;55(2):65-73
33 Kalaivani K, Ramachandran P. Time trends in prevalence of anemia in preschool children in India. Ann Natl Acad Med Sci (India) 2019;55(1):18-23

34 Del Bello L. Fluorosis: an ongoing challenge for India. Lancet Planet Health 2020;4(3):e94-e95 